\title{
In Greensight: Healthier Futures for Urban Cores in Transition
}

\author{
Ana Maria Jones, Markku Wilenius
}

(MSc. Ana Maria Jones, Finland Futures Research Center, Korkeavuorenkatu 25 A 2, Helsinki-Finland, ana.jones@utu.fi) (Prof. Markku Wilenius, Finland Futures Research Center, Korkeavuorenkatu 25 A 2, Helsinki-Finland, markku.wilenius@utu.fi)

\section{ABSTRACT}

This paper develops new perspectives of cross-disciplinary methods combining futures studies and urban planning to help imagine healthier futures for compact urban cores. Our empirical basis lies in researchbased collaboration between 2016 and 2019 with the City of Turku, the former capital of Finland. The goal was the creation of an ambitious but realistic vision and strategic plan focused on liveability and wellbeing and addressing challenges posed by spatial fragmentation and lack of cohesion. Through the process, it was concluded that to create a positive transition, planning requires the adoption of a 'greensight' perspective as a point of departure. The basic argument was that in order to reach a new level of human-centredness and interconnectedness, urban cores need to act as the strong support system for the healthier urban societies of the future. In this paper, we explain the lessons learned and provide an analysis of green areas in the context of Turku. We share wisdom on two key aspects: 1) the growing importance of human health for a more future-oriented approach to the planning of green areas and 2) the rising levels of urban complexity that make adequate distribution of green areas hard to achieve.

Keywords: wellbeing, urban green, future studies, transformation, urban cores

\section{INTRODUCTION}

One significant trend in urban development across European cities and elsewhere is the growing consensus that life in urban centres needs systemic integration of green areas and more understanding of how to reconnect with nature for human and planetary wellbeing. To explore this field of knowledge and for the purpose of this paper, we have used the term 'greensight' to refer to trends and systemic viewpoints that bring focus to the importance of green areas and the considerations needed for their integration with the built environment. Calling attention to a series of viewpoints, the perspectives below support the theoretical rationale of this paper; they explain why a focus on green areas is crucial:

(a) Green Spaces for Human Health: An extensive body of research in the field of environmental science has already demonstrated how exposure to a diverse range of nature areas has a positive cognitive, emotional, physical and mental impact on people living in cities (Bertram and Rehdan 2015, Ode Sang et al. 2016, Van den Berg et al. 2017, Akpinar 2017). In his book Everything in Its Place, the physician and pro-fessor of neurology Oliver Sacks explained 'why we need gardens.'(Sacks 2019) According to his observations, gardens are essential to the creative process. He went on to refer to them as a type of "non-pharmaceutical "therapy" of vital importance for improving positive physiological states:

I have a number of patients with very advanced dementia or Alzheimer's disease, who may have very little sense of orientation to their surroundings. They have forgotten, or cannot access, how to tie their shoes or handle cooking implements. But put them in front of a flower bed with some seedlings, and they will know exactly what to do-I have never seen such a patient plant something upside down (Sacks 2019, p. 245).

Dr. Sacks found that gardens and nature were more powerful than medication - a key aspect when we consider the health benefits nature provides for human development and for supporting more resilient societies. The observations by Sacks on the positive effects of gardens on physiological states underscore the innate human restorative and healing powers that can be assisted by nature and the vital role they play in mental healing. Indeed, research in the field of urban psychology has already called attention to the relationship between the human mind and the physical environment. Studies have, for example, found a correlation between urban living and poor mental health. In his book The Psychology \& the City: The Hidden Dimension, Charles Landry mentioned how urban populations are twice as likely to experience schizophrenia and almost three times as likely to experience depression than populations in rural areas (Landry and Murray 2017). Also, it is worth noting the growing traction of mental well-being in the global development agenda and its integration with mental health in Goal 3 of the Sustainable Development Goals (SDGs). 
(b) Changing narratives, from linear to circular: Beyond human health, nature is essential for biodiversity and planetary well-being. Our natural environment is composed of a compact dynamic network working on a closed and efficient cycle that is highly interdependent and collaborative (Siegel 2018). Even if the tendency in our physical environment is towards a more individualistic, hierarchical and man-dominated society, the truth is that the natural world works in the opposite direction. The laws governing the natural world are known to be non-hierarchical and non-linear. Contrasting to this are linear models which have been defined as characteristic of terminal cultures (Johnson 1991). The way urban systems operate today shows that natural and material cycles lack the capacity to restore creating inefficiencies, the extinction of species and generating excessive waste. This only indicates that our current model for development is unsustainable, something that becomes apparent every time we choose to replace nature's functionality and intelligence with the purely economically-driven expressions of our past industrial societies. So, what we see now is a society that has purposely sought to break away from nature and its environment both to its own detriment and to that of future societies. We have essentially created a broken link within our total ecosystem.

(c) Nature biodiversity for urban resilience: Nature networks are multipurpose. The specific role played by any living organism in the effective functioning of ecological networks is pivotal for both evolutionary processes and for building intelligent and resilient environments. In fact, many cities such as Bogota or Los Angeles, to name only a few, have evolved in some of the most fertile and biodiversity-rich landscapes and regions. Biodiversity in this context means diversity of life. Los Angeles is known to be part of a biodiversity hotspot called the California Floristic Province - one of thirty-six biodiversity hotspots in the world (Higgins et al. 2019). Cities located in close proximity to these hotspots are also required to implement urban conservation measures that preserve a habitat in which native and foreign species can thrive and sustain. Conservation also provides opportunities to integrate biodiversity in a wider programme for human health. Cities and citizens depend on the healthy regulating effects of natural cycles for a number of functions, like the provision of clean air and clean water, local climate regulation and education, For these reasons, green areas like parks act as hotspots for biodiversity; they create the necessary conditions for species to thrive and for people to experience nature's healing benefits.

d) A futures approach to urban transitions: Some people would argue that the word 'nature' did not exist in previous ancestral interconnected cultures when humans and nature were part of an integrated system that did not differentiate between the two. This implies that differentiation between the human and the natural was indeed created by man himself. Futures research has been particularly concerned with the sustainable evolution of our natural world. The Finnish futurist Pentti Malaska contended that humans were being gradually separated from nature (Pouru et al. 2017). He reflected upon 'the stage of ecosystem predominance' and how human material existence was from the beginning controlled not only by the same invariant laws of nature as the rest of the ecosystem, but also by the initial cosmic boundary conditions prevailing within it. But how far have we gone from our innate connection with our biological systems? And what are the tools that will help transform our environment and present alternatives for a different type of connection with nature? One possibility is a futures thinking approach. Foresight and futures studies essentially make two contributions to urban development: a) a vision of the future exploring alternative (ideal) scenarios not visible in the present time and b) the tools to enhance participation and to have a positive impact on the future. In essence, a futures approach contemplates alternative pathways that can assist transformative processes towards more informed and diverse solutions.

(e) Systems complexity and transformative processes: Complexity theory is part of futures research. Within the field of complexity theory, and the way in which it is applied to urban systems and ecological transformations, the imbalances in existing systems and frameworks constitute a recurrent theme (AlvarezPereira 2016). This is manifested directly in the fragmented landscapes of city cores and the minor role that nature usually plays in them. Across city planning, there is a tendency to work in silos. Small independent patches of green do not contribute a sense of the complex and interconnected whole and do not provide impetus for inspirational experience. The essential benefits of nature are indeed invaluable. Yet it has been difficult to put a price on the intrinsic value of nature for our human and planetary existence - something that has contributed to the undervaluation of nature areas and their ecosystems for human well-being. We could say that our model for development has led to nature being poorly understood, grossly undervalued and ineffectively managed. 
(e) Urbanisation and compaction: Population growth is a key driver of urban change. According to the World Health Organization (WHO), more people live in urban areas than in rural areas (2018). In the 1950s, 30\% of the world's population was urban. Today it is estimated that by 2050 , the urban population will account for $68 \%$ of the global population. Population growth and unregulated development are to be blamed for urban inequalities. Inequalities in cities have followed an invasive model of urbanisation - car-driven development with buildings and other urban infrastructure detached from natural cycles. The absence of a systems level has resulted in a parasitic relationship between nature and the built environment. The history of urbanisation goes back thousands of years. According to Landry and Murray (2017), 'modern humans have been around for 200,000 years but cities only for 6,000 to 8,000 years'. Success cases have been based directly on access to land and natural resources like the water and soil needed to sustain the biological and artificial constructs of cities. The compaction of urban areas is a driving factor for change in the urban landscape and planning structure. The current trends in urban cores with urban-tech and the flood of large companies, millennials and other groups gravitating towards centres poses a challenge for maintaining access to nature resources and urban equality.

So, what is having a greensight view mean against this background? It means resourcing to alternative mechanisms that can facilitate new types of governance, planning structures and very importantly, a change in narrative. It also means promoting the emergence of a constructive dialogue centred round the interrelated capacities of circular systems - network design, organisms and urban systems. Current urban transitions require methods that challenge our preconceived notion of linearity and individuality. We need to learn from nature to come back to the sense that we are part of a whole, that alone we are unable to go far let alone sustain.

Increasing awareness and understanding of the effect green areas have on human health is crucial for transforming cities into environments that breathe life. In the following section, the City of Turku, the old capital and one of the biggest cities in Finland, is introduced to share experiences and lessons learned on previous work where futures foresight methods were used as part of an urban analysis of green areas. In addressing challenges, the study also explored the potential of green areas to help tackle urban challenges of urban fragmentation, lack of cohesion, and liveability. Back in 2017, the City of Turku launched its City Centre Vision 2050, which was drafted by a Vision Committee led by Markku Wilenius (Turku City Center Vision, 2050). Through the use of foresight, a new agenda for the city centre aimed to invite a more accessible, liveable and healthier Turku. The vision led to a critical analysis of the city centre landscape and subsequently to development of the sub-project Green-In Turku: Towards Greener Urban Futures. The aim of the sub-project was to study Turku's network of green areas and their hidden potential. Key observations were made primarily on how to improve access to and adequate distribution of multifunctional green areas. Another aspect highlighted during the vision process was the lack of systemic thinking and the importance of foresight as a useful tool to anticipate challenges and opportunities and to open up the possibilities for having a positive impact on the future

\section{A GREENING VISION FOR URBAN CORES 1}

Green areas are important sources of information and wellbeing. Nature is in itself a diverse, collaborative and intelligent system. In contemporary urban settings, green areas are spots where nature has the possibility to flourish; yet, green areas are often overtaken by grey development based highly on economic targets inherited from a culture of the past that believes in endless economic growth. A greening vision for urban cores looks to promote a change of direction to break away from that past to inspire new ideas in search of a more promising future, no longer based purely on capitalistic, financial or economic values, but focused instead on the health and wellbeing of people and communities and on resolving the most pressing societal challenges of our time to benefit those who live, work and participate in urban life.

Green areas are the lungs of every city. In studying the dynamic flows of urban centres, analyses with spatial quality criteria, geographical and demographical data demonstrated the need for more research in the field of green space planning and networks to understand who are the users and what are the specific needs that we need to respond to. Ecologically, urban planners will need to expand their understanding of the nature of services and disservices generated by green areas and their regulating, supporting, and provisioning capabilities. In the face of an increasingly urban population, concentrated mainly in compact built-up areas, 
green spaces and biodiversity hotspots will become of strategic importance as areas with the highest potential for making a positive impact.

\subsection{Greening Turku City Centre: Key Messages and Lessons Learned}

This paper draws from close collaboration between the Finland Futures Research Centre and the City of Turku that took place between 2016 and 2019. The collaboration was an exploration into the possible futures for the city centre of Turku, formulated in the Vision and strategic plan 2050 for a more liveable and humancentred city. In an attempt to tackle challenges of spatial fragmentation, lack of cohesion and urban attractiveness, research was carried out on the state of Turku's green areas to identify points where the quality, distribution and access to existing green areas could be improved and also to explore new potential looking beyond marginal planning. The project combined a series of foresight methods and analysis of patterns in urban-core development. In addition, site observations, interviews and surveys complemented the analysis. The outcomes were presented to Turku's city officials as a set of 13 recommendations for how to improve the urban green layer of the city and its liveability profile (Jones and Wilenius 2018b).

The City of Turku is a medium-size, 800-year old city located in Southwest Finland (See Figure 1). The total area of Turku is $306.4 \mathrm{~km} 2$ with land accounting for approximately $245.7 \mathrm{~km}$. Turku is located in an

archipelago region of 20,000 islands and is a port of entry for trade between Europe and Scandinavia. In 2017 , the total population of Turku was 189,669 people of which some 56,000 lived in the city centre. The city centre population in 2018 was predominately divided between young and middle-aged groups. The largest age groups living in the city centre in 2018 were between 20 and 59; they accounted for more than half of the total residents of the city centre or 35,380 people, thus indicating the predominance of a relatively young community. The following paragraphs explain a series of key messages and shortcomings that emerged during the research that was conducted between 2017 and 2019 on urban green areas in the city of Turku:
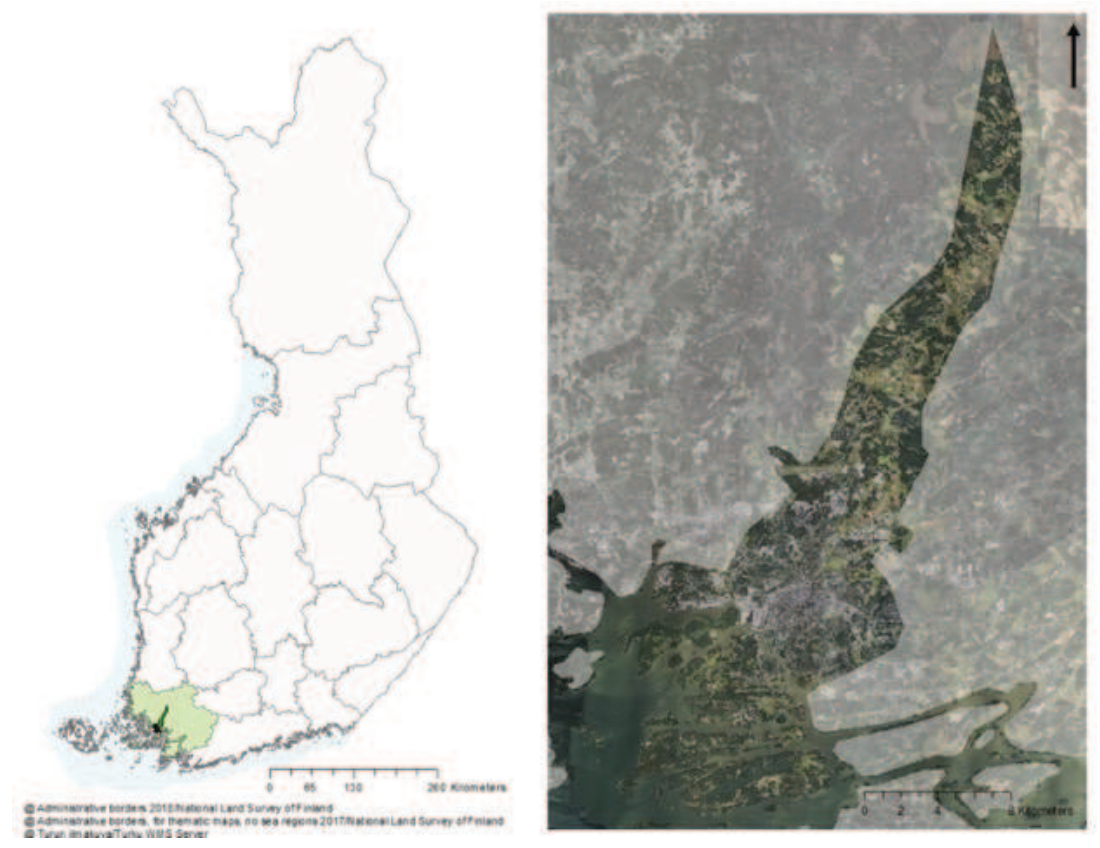

Figure 1: Aerial map of Turku: Turku's location in Southwest Finland (National Land Survey of Finland 2018).

Leadership: Shortcomings in planning showed to be related to the lack of a clear vision on the side of local authorities from design and planning, who strongly prioritised the intactness of the design and function of the City's historic parks and view improvements or changes as unnecessary. This approach leaves unsolved the question of how historic parks could be elevated and what new visions for the future of green areas can be imagined. Ultimately, green areas need to be planned in direct relationship with their urban context with consideration especially for the wide range of users who are direct beneficiaries and also stewards of the land. The challenge that remains with this approach is how to identify the right point of intervention that would significantly enhance the value of green areas; also, what actions could best support the holistic integration of a green network in the future. In the case of Turku, the lack of systemic thinking in leadership 
posed difficulties on the implementation of results and how the city could capitalize on the advantages of foresight as a decision-making tool in planning.

Planning: In planning, green area size matters. Measurements are essential for developing baselines and for comparing the proportion of green areas to grey areas. Yet, at the time of our study, an inventory of green areas including small and large pockets had not been produced by officials in charge of landscape planning. We found that while the master plan did include a list of the parks owned by the city, areas on private or semi-private lots were excluded. To assess the significance of the supportive and functional benefits of green areas, it is necessary to expand the scope of the areas under study and approach them as a complete system. This approach should be part of a critical analysis looking into the specific roles that green areas play for human health. Furthermore, in the centre of Turku, the majority of the public parks designated for recreation also include facilities such as buildings, playgrounds, football fields and tennis courts. These are paved areas that no longer perform the same ecological function that supporting systems of "green" vegetative surfaces are meant to perform. A change in the specific function of a green area means that its purpose is also changed. Thus, interventions in urban green areas need to consider a systemic approach, which means that under changing conditions, the quality of the entire area also needs to be reassessed.

Access design: In Turku, a human-centred design approach that carefully considers access to green areas needs further study. Due to its topography, Turku's green areas, i.e. a large number of parks, are mainly located on hills and slopes, making assessment of size and area a challenging task for planners. Universal access is a major challenge, particularly for people with mobility constraints, children and elderly people, since green areas for recreation are mainly reached through stairways or ramps. Challenges also remain concerning access points at street level, which were difficult to locate and when found, they lack universal access design. If the aim is to invite people to the experience of living in a city with good access to green space a diversity of functions and activities, the design of access points in the case of Turku is going to require further design and planning. In general, green areas can offer much more functionality and design than they do today. Proximity to a green space can be measured as a linear distance of 300 metres or 15 minutes of walking time. The proximity indicators in Turku should consider a broader area of coverage beyond the limits of its current central axis. This is particularly important for those districts of the CBD with no available green space.

\subsection{The City Centre Vision 2050 Toward a New Turku}

The overall Vision 2050 for the city centre developed into three primary objectives: a) an accessible and walkable centre; b) a commercially attractive centre with active green areas and public ground; and c) an engaging and vibrant social space. Awareness of the need for fundamental change in priorities stemmed from localised challenges confronted at the intersection of the commercial, historic and university districts. Some of the main challenges found were particularly related to the following:

- New development prioritising the surrounding areas of the city core. The tendency towards offcentre development, which led to fracture in planning - something that remains evident today.

- Internal deficiencies within city planning departments and local authorities and the lack of a systems-based approach and an interdisciplinary mix of sectors, disciplines and civic society as the major contributors to the process.

- The tendency towards shopping malls and other commercial development near the historic district something that tends to transform public spaces into silent spaces and ultimately results in a less active urban life.

- The lack of human-centred design and approaches to facilitate more and better access to small and large green areas for different functions, i.e. how to connect parks on hills and slopes with street level access points on the ground as part to encourage a larger interaction of people and nature.

During the implementation of the Vision, other concerns were related to leadership efforts and poor decision making. The overall process exposed some important gaps between the tasks performed by city planners and what is actually feasible or implementable. In Turku, there is a strong tendency towards keeping the status quo. Much less importance appeared to be given to meeting targets and exploring new potential. 


\section{APPROACH TO ACCESS QUALITY AND DISTRIBUTION OF GREEN SPACES}

Nature is transformative. By increasing access to green areas, cities restore opportunities for improving the quality of life and human development in citizens. A "good" quality of life means, among other things, that all groups of society can enjoy equal access and opportunity for encounters with nature in their immediate environment. In urban planning, increasing access to green areas means the study of green areas as the essential connecting tissue, linking the artificial urban structure with essential self-regulating ecosystems necessary for life. So, to increase understanding of the multiple concepts that could help improve access to green areas, the term access is explained here through the lens of the following three concepts (see figure 2):

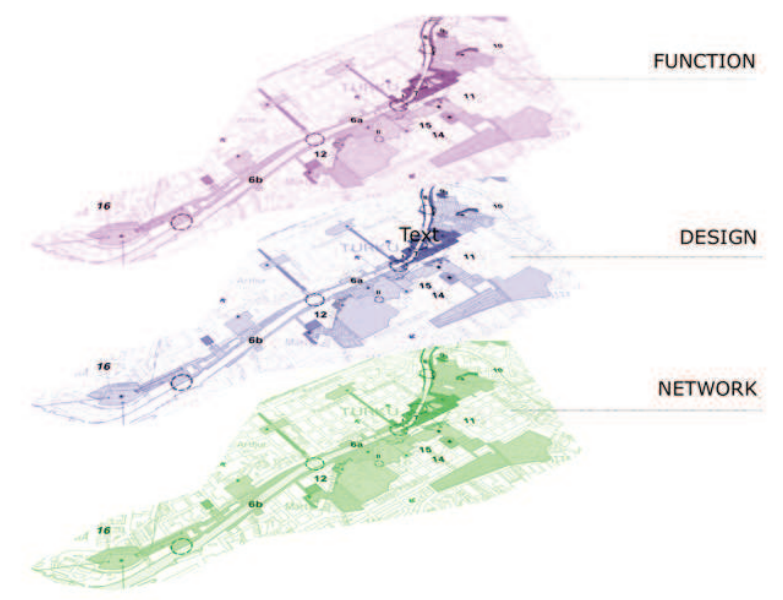

Figure 2: Approach to access, quality and distribution of green spaces ${ }^{1}$

1. Network: A network approach to working with green areas entails the study of a set of green spaces often classified as parks, recreational areas, sports facilities, green pockets, social spaces, and green streets. Areas combine to form the green interconnecting layer upon which the life-supporting systems of the city depend. This approach to work in a network connecting small and large pockets of green areas enhances ecosystem properties and the potential for emergence of new functions. From this perspective, access to green spaces will mean a system of green spaces integrated as part of a larger unit, in other words, a network that is circular in process and dynamic and flexible in nature. It also refers to the self-regenerative properties of the urban green layer and how its properties can be self-sustained, self-preserved and self-regulated.

2. Design: In the urban context, access to green requires a human-centred design process that considers the multiple dimensions of nature's intelligent design. When we consider green areas, the right design should ensure the right access for a given area. Provisions need to be made for inviting, universal, attractive and aesthetic access with consideration of future trends in changing environments. Design also means consideration for the network's node and accessibility, not only facilitated by design but also optimized. Here, careful design can enable solutions for building better linkages between green spaces, pockets and pathways with mobility, and other networks. Design for green public space should enable better connectivity between neighbourhoods, linking urban cores with surrounding areas.

3. Function: The function of green spaces is crucial. Green pockets, passages, and pathways must be designed with a specific purpose in mind. This means that the layer of ecosystem functions for well-being facilitates social and human development for those living in densified areas. For example, in the case of Turku, improving access to green areas will require a detailed inventory of the size, number of areas and accessibility of green spaces, individually but also as part of the overall system. A detailed inventory provides information useful in identifying gaps and inadequacies in the network and can assist planners in settting benchmarks for the city's minimum accessibility targets as part of a social and ecological strategy.

\footnotetext{
${ }^{1}$ Jones, Ana \& Wilenius, Markku (2018b). Access to Green; Enhancing Urban Attractiveness in Urban Centres - the Case of Turku. FFRC eBook 6/2018, Finland Futures Research Centre, University of Turku.
} 


\section{THE ROLE OF FORESIGHT AND FUTURES STUDIES IN URBAN PLANNING}

In futures studies, foresight has the potential for making the invisible visible. Foresight is a window on not one but multiple pathways that can support city planning processes; yet, in the absence of strong strategic decision making, the real potential of foresight for materialising ideal futures would not be impactful. Our approach in this article was built on the premises of futures studies. One of the basic assumptions of futures studies is the notion that the future has many emerging properties. This explains why the future is seldom part of a direct continuum with the past. These emerging properties form a complex web of future interconnected phenomena. That is why futures studies are closely connected to systems thinking, which teaches that interrelations often matter more than the phenomena themselves (See Wilenius 2017).

In terms of foresight, determining our anticipatory assumptions about how the future will unfold is a key aspect (Fuller 2017). So, from the perspective of anticipatory systems, we need to ask how this central aspect of health - and more and better access to green areas to achieve more health - will evolve in the future. And what is the role of health in organising the physical and social space of cities?

In order to respond adequately to the above questions, we need to take a broader look at current urban transformations and their implications for the future of life in cities. From the perspective of futures studies, urban change occurs in its local context. In urban life, the modernisation and industrialisation of the last 200 hundred years has caused massive changes in the way cities are built, creating every unique human experience (Berman 1982). Cities are living entities that adapt constantly to change, some suffering from unsustainable growth. At this point, we cannot expect that the pace of change will slow; on the contrary, the general sense is that cities will continue to experience growth in the years to come.

In futures studies, weak signals are a key tool for understanding future trends. By definition, weak signals refer to phenomena that initially seem no more than background noise, but which, when connected to other phenomena, can begin to emerge as a pattern (Hiltunen 2010). Autonomous cars are an example. Ten years ago, almost no-one anticipated that driverless cars would be roaming the streets. While autonomous cars have of course been tested for some

100 years, they have nevertheless been relegated to the future and the world of prototypes. However, they have now become a reality, at least to the extent that the first real autonomous vehicles have already been deployed in cities.

Here we point to three major weak signals in today's urban context: First, changing values. According to research, values are becoming 'post material', as described by Professor Roland Inglehart in his World Value Survey (http://www.worldvalues survey.org/wvs.jsp). There is a shift from basic survival needs towards a new set of needs; today's generation values time and social connections more than its predecessors. It is worth noting that spending time in nature has become a dominant trend across multiple spheres of development.

These signals of changing value systems could be connected to a larger shift in our societies. This shift is akin to the transformation from agricultural to industrial societies some 200 hundred years ago. Now we are taking the next step, moving from an industrial society to a more service-orientated, intimately networked model of society. In futures studies, this transition has been dealt with in various ways (Wilenius 2017). One very perceptive approach concerns the shift from a society of tangible needs towards one of intangible needs advanced by Professor Pentti Malaska, founder of the Finland Futures Research Centre. According to Malaska, we are right now in the interim phase, as tangible needs are yielding to higher, intangible needs via a dynamic process, as Figure 3 shows (Pouru et al. 2018):

In the first phase, the main focus is on fundamental needs such as food, shelter and clothing. Society is mainly organised around satisfaction of these basic needs. At the next stage, these needs are superseded by tangible needs, and society is restructured with a view to satisfying them. Eventually tangible needs give way to intangible needs and society reorients itself to meet them (Pouru et al. 2018).

Malaska himself explained these transitions in the following way: 'Agrarian society satisfied basic needs, industrial society has satisfied tangible needs.' It is now becoming increasingly clear that people have needs which cannot be met with goods. These are particularly the needs for social situations, encounters, conversations, human relations and human contact. These needs can only be satisfied in the presence of another person. Agriculture has not disappeared in industrial society, but it has been transformed. In a similar 
way, industry will not disappear from modern society, but it will instead require increasingly less input and effort.

In the future, we propose - in the spirit of Malaska's findings - that we will consume ever larger volumes of human relations and that this will happen increasingly in the urban context. The particular benefit of the modern city life is that meeting different people has become really easy. He also foresaw that a new type of family network will also evolve - a community of people who live together even when relationships have outlived their capacity for reproduction within the community.

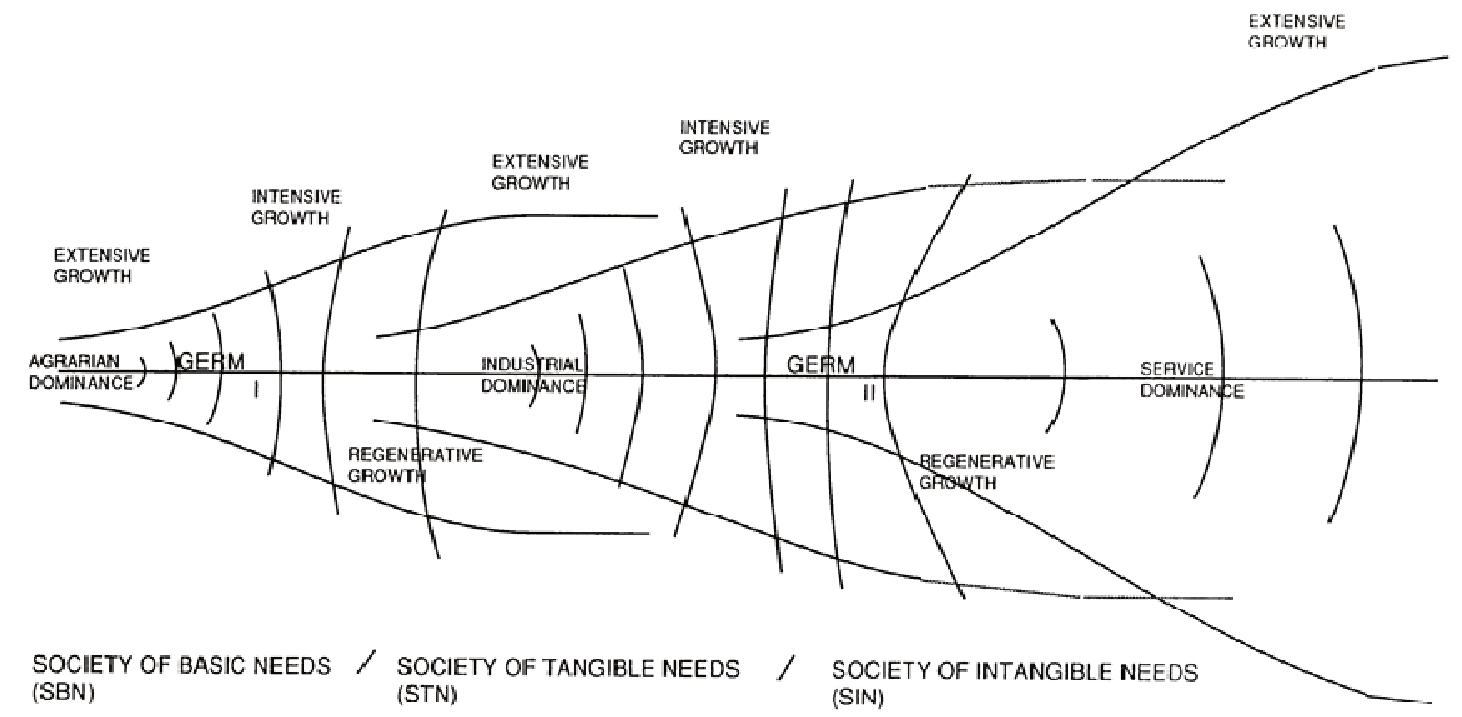

Figure 3: A model for social transformation dynamics (Malaska 1999).

To quote Malaska, 'So, are humans capable of changing? They certainly are. Just compare the situation today with agrarian society, where children worked in the fields rather than lazing around at school. This is the kind of world I would like to build in the future' (Turun Sanomat [Turku News] 1983).

While tangible needs have been largely provided by the massive material production of industrial society, as described by Abraham Maslow through his pyramid of basic needs, these new, intangible needs are on a much higher level; they are related to the search for the meaning of life itself. They are best served by a specific set of dynamic, active skills that signify a shift to the $21^{\text {th }}$ century social environment. These skills could be described as follows, in terms of the challenges facing our changing global environment (Gerbrands and Wilenius 2020):

(a) Planetary living skills: How do we create a healthy relationship with our physical environment?

(b) Complexity skills: How do we manage the overwhelming amount of information and keep our thinking clear and consistent?

(c) Creativity skills: How do we enhance our capacity for finding new and unconventional solutions to the problems we face?

(d) Empathy skills: How do we grow our capacity to see issues from the perspective of others?

Building these skills provides the foundation for urban development in the same sense as the birth of industrial society created the basis for urban expansion in the previous two centuries. While providing for basic needs such as food, jobs, and relationships shaped the physical construct of cities with factories, car-fit streets, residential areas and shopping malls, deploying a new set of active skills will create a very different kind of physical space. Here we see the emergence of social, non-commercial spaces like citizen's parks and new concepts for libraries, mixed housing environments, office space, cafes, pedestrian and bike lanes. City cores become more human in scale as these intangibles needs are met through the regenerative growth of the human experience coupled with an extensive period of growth in the service sector.

In this upcoming phase of human development, health becomes an altogether different field. While 'health' primarily concerns our physical well-being and capacity to provide for basic needs in the era of tangible needs, the mentally loaded notion in the era of intangible needs takes a more holistic approach. 
In the phase of intangible needs, we start to observe and emphasise very different things; for example: the role of green areas in creating solace for the mind and how they stimulate the senses, the absence of pollution of any kind in our immediate environment helps us to stay in a good mood, or the opportunity to exercise in the middle of the city to keep our bodies and minds fit. Although these features played a minor role in shaping urban development over the last 200 hundred years, they have suddenly assumed importance in our city design.

Moving to a society of intangible needs has many implications for physical space. It will pose major challenges for city design, which has traditionally been built around physical and social infrastructure, housing and mobility. The quality of experience will become the central focus of design. A look at contemporary city core design, however, often reveals little evidence of such values. The automobile continues to dominate, as it has for the last 70 years.

All in all, intangible needs will grow in importance while resource efficiency will become a key factor in organising our material world, as the 'K-Wave' framework theory implies (Wilenius 2017). In this way, societies will start to realise the potential in nature's design in a completely new way.

There are also multiple implications for the new role of nature in cities. In our studies of urban places, we detected numerous signals of a new appreciation for the urban experience (Jones and Wilenius 2018a). In most of the major Nordic countries, cities have taken major steps on these fronts: more light for city centres, more right-scaled pedestrian streets, and more activities that play out in the streets. And many more green, multi-functional areas.

We estimate that what we have been observing as weak signals, indicating a change in the paradigm of urban city core planning, are about to transform into a major shift towards a greener design principle-all this is occurring because of the shift towards a society of intangible needs described above. Hence, what we call greensight in this article will enhance its role in overall city development in a massive way as we move further into this century. With the shift towards post-material values, people will begin to appreciate nature in a new way. They will want parks instead of parking lots. They will want non-polluting, electronic mass and individual transportation systems. They will want urban forests or gardens instead of another shopping mall. Greenness will be at the core of the desired urban experience because it is increasingly important for people to bond emotionally, as technology and digitalisation continue to expand. Nature is an essential counterbalancing factor here.

Yet, for the time being, we need to admit that the old non-human-centric design still holds sway in most cities. Despite some exceptions, most city centres simply look artificial and bare; they are primarily built with concrete, and buildings' design, and materials lack the sensual aspect and human-centredness as well as a deeper psychological understanding of human nature and how it interacts with the built environment. Here, the 'return of the human perspective' remains a weak signal. Most cities still belong to this group, and even if they have many green spaces, they are not yet working sufficiently to enhance the urban experience in the context of urban nature and biodiversity. The approach to design and planning green areas in these cities remain an afterthought where the focus is on adding more concrete-based structures, taller buildings and more cars.

As we move further into a society of intangible needs, cities will become much more interactive and dynamic. In the future, we believe, cities will make increasing use of their citizens' ideas on how to design common spaces such as gardens inside city centres or suburban areas. Agendas of this type will become necessary for all cities as a form of complexity management. By engaging more inhabitants and users in the design, planning and implementation of urban policies, we can ensure more sensitive processes along the way. The only adequate way to handle this ever more complex environment is to enhance the feedback loops in the system as cities become ever more complex sets of technologies and infrastructure, with more data available for everyday operations.

\section{LOOKING AHEAD: PERSPECTIVES FOR DEPLOYING SYSTEMIC THINKING AND GREENSIGHT}

As we have previously mentioned, a systematic approach to restoring green areas in cities is still not a dominant trend in planning. In spite of our dependency on biological systems for wellbeing, integration of 
green areas remains a type of patchwork or is not seen as the foundation upon which we should build the cities of the future.

Applying greensight in this case means adopting policies that are more intelligent, non-partial, inclusive, and holistic. Within these policies, promotion of green areas and ecosystem functions is not relegated to a marginal agenda in city strategy. On the contrary, it is meant to elevate these areas to centre stage, not just to create healthier and vibrant cities, but also to ensure a sustainable environment, attract innovation and investment. Thus, we argue that greensight - as we have defined it - will need to become a centrepiece in policy talks where the focus will increasingly be on how to tackle critical issues of air pollution, climate change, and biodiversity loss.

Working with a new agenda for integrating nature and urban areas in the future presents multiple challenges to the old planning paradigm, but also opportunities to innovate. What we refer to as greensight means new thinking towards a certain set of principles and policies that should be employed rigorously to design and redefine the cities of this century. The following principles were born out of our most recent research and observations of some of the most proactive cities which are showing signs of moving away from the conventional to redesign and integrate green areas holistically. These new approaches open up a new line of questioning and inspire new ideas for how urban cores could be dealt with. The following are some of the main drivers we have identified as promoters of urban change:

(1) Complexity management: Complexity management requires understanding of a systems-based perspective - how cities adapt, self-organise, and change over time. In most progressive cities, the trend has been toward taking the human-scale approach as a starting point; therefore, minimising challenges; for instance, cycling in a city centre designed for cars. Complex systems are characterised by uncertainties and discontinuities. As we advance in our agenda on complexity management, it becomes increasingly important to analyse 'blind spots' in the urban context, i.e., areas to which our sectoral, sub-optimal policies do not readily pay sufficient attention.

(2) A new intelligence: Cities are looking for untapped potential and intelligent approaches in the unconventional; also, by working with new actors engaging them in the planning process, one example is the city of Barcelona. Barcelona has already earned recognition for some of its intelligent actions in educating the community in participatory and democratic processes. The successful implementation of the Superblock programme and action plan has its roots in the active participation of community and neighbourhood organisations during its design. The main priorities focus on quality of life and on expanding the city's green network that recognizes the need for high-quality public space for activities, experiences, recreation and biodiversity. In the case of smaller cities with fewer resources available to scale-up initiatives, the adoption of intelligent solutions on a smaller scale is proving to have the potential to generate big results. Smaller cities are using their advantages in terms of scale, human, social and cultural capital, to innovate. In some of the neighbourhoods of Sydney, the small-scale reactivation of laneways and fine-grain spaces is an example of how resource efficiency is used for turning underutilised hidden lanes into greener, vibrant urban blocks.

(3) Diversity and the mixed city. Planning for mixed and diverse cities creates opportunities to attract a wider range of users and boost social capital. The need for diversity in groups, users and functions opens up new perspectives for how multiple collaboration channels expand the network of connections in the urban landscape. In the case of Vienna, an urban strategy for green and open spaces considers flexibility in planning with a focus on future generations. In this case, the planning for multi-functional green and open spaces puts emphasis on social diversity to provide all groups with good access to areas where people can play, meet, and be social. By focusing on green areas, cities can promote change by inviting citizens to learn about the natural world. Learning in this context could have ample potential for creating a sense of responsibility and stewardship in those who participate.

We believe the above-mentioned drivers of change could provide the bases for what can be called 'system policies' for enabling greensight to take place at the decision-making level (Schmidt-Bleek et al. 2014). Our argument is that only serious consideration to these aspects is what will ensure the sustainability of 'healthy' cities in the long run. Here, we move beyond issues related to human health in connection with green areas to suggest that the city itself will develop an awareness of its potential by deploying more systematic and complexity-conscious policies. 


\section{CONCLUSION}

Our relationship with nature is the most transformative challenge of our time. Developing a systems-based approach to increase access to green spaces in urban areas will mean a shift in paradigm towards a more human-centric planning. Our basic argument is that for development on a global scale, this new kind of approach to urban design will probably be the only way cities can thrive as centres for human development and interaction in the future. Already in the next decade, we shall see how an increasing number of cities, some faster, some slower, will add green design methodologies to their toolbox. This happens because people in cities are developing a new consciousness and willingness for change and activating themselves against the low quality of life and the stresses of environmentally harmful development. This indicates the emergence of a new, more environmentally-savvy generation, who we believe will lead this transformation.

If the weak signals we have observed were to become dominant, it would mean that the design of urban areas from the perspective of health and the wellbeing, would, we believe, be of central focus. Cities, which have a long history of negative effects on mental and physical health because of the pollution, noise, congestion and stress they generate, will become labs for positive and healthy life. While we are still far away from that ideal, at least we already see the first signs of development that may bring us closer to a much healthier life in urban settings.

In this upcoming new phase of human development, the field of health will become an altogether new field. While 'health' in the era of tangible needs is primarily an issue or a risk for our physical well-being and capacity to provide for basic needs, in this current era of intangible needs, urban health will need to take a more holistic, mentally loaded notion of wellbeing.

\section{REFERENCES}

Akpinar, A., 2017. Urban green spaces for children: A cross-sectional study of associations with distance, physical activity, screen time, general health, and overweight. Urban Forestry \& Urban Greening, 25.

Alvarez-Pereira, C., July-August 2016. Towards a society of living: provocations on economy and economics by Layman and entrepreneur. e-Journal of the world academy of art \& science, 2 (2), 72-101.

Berman, M., 1982. All that is solid melts in the air. The experience of modernity. New York: Simon \& Schuster. Bertram, C. and Rehdan, K., 2015. The role of urban green space for human well-being. Ecological economics, 120 (C), 139-152.

Fuller, T., 2017. Anxious relationships: the unmarked futures for post-normal scenarios in anticipatory systems. Technological forecasting and social change, 124 (2017), 41-50. doi:10.1016/j.techfore.2016.07.045.

Gerbrands, P.P. and Wilenius, M., 2020. Connecting to the future. How to reach the next step of human development. London: Little Brown.

Higgins, et al., 2019. Wild LA: explore the amazing nature in and around Los Angeles. Portland: Timber Press Inc.

Hiltunen, E., 2010. Weak signals in organizational futures learning. Acta universitatis oeconomicae helsingiensis, A, 365.

Johnson,C., 1991. Green dictionary. UK: Optima.

Jones, A. and Wilenius, M., 2018a. Access to green; enhancing urban attractiveness in urban centres - the case of Turku. FFRC eBook 6/2018, Finland Futures Research Centre, University of Turku.

Jones, A. and Wilenius, M., 2018b. A green urban future. Scaled-up perspectives in urban green for human-centered and livable urban cores. FFRC eBook 5/2018, Finland Futures Research Centre, University of Turku.

Landry, C. and Murray, C., 2017. Psychology \& the city: the hidden dimension. UK: Comedia.

Malaska, P., 1999. A conceptual framework for the autopoietic transformation of societies. FUTU-publication 5/ 99. Futures Research Centre. Turku School of Economics and Business Administration, Turku.

Municipal Housing in Vienna, History, facts \& figures. City of Vienna.

National Land Survey of Finland, 2018, https://www.maan mittauslaitos.fi/en.

Ode Sang, A., et al., 2016. The effects of naturalness, gender and age on how urban green space is perceived and used. Urban forestry \& urban greening, 18, 268-276.

Pouru, et al., 2017. Pentti Malaska: a visionary and forerunner. Turku: Finnish Society for Future Studies.

Pouru, L., et al., eds.. 2018. Pentti Malaska-a visionary and forerunner (futures series 9). Helsinki: The Finnish Society for Futures Studies.

Sacks, O., 2019. Everything in Its place: first loves and last tales. New York: Alfred A. Knopf.

Schmidt-Bleek, F., Wilenius, M., and Lehmann, H., 2014. The challenge of the whole. Creating system policies to tackle sustainability. In: M. Angrick, et al., ed.. Factor X: policy, strategies and instruments in the sustainable resource use. Springer Verlag, 137-147.

Siegel, D.J., 2018. Aware: the science and practice of presence. New York: TarcherPerigee.

Turku City Center Vision, 2050, http://www.turku.fi/en/ vision2050.

Turun Sanomat [Turku News], (1983, August 28). Tavaroiden sijasta tulemme kuluttamaan ihmissuhteita. Instead of Goods, We Will Consume Human Relations.

Van den Berg, et al., 2017. Does time spent on visits to green space mediate the associations between the level of residential greenness and mental health? Urban Forestry \& Urban Greening, 25.

Wilenius, M., 2017. Patterns of the future: understanding the next wave of global change. London: World Scientific. World urbanization prospects. The 2018 Revision https://population.un.org/. 